\title{
Hepatitis B and Hepatitis C Reactivation in the Biologic Era
}

\author{
Lizza Bojito-Marrero and Nikolaos Pyrsopoulos*
}

Division of Gastroenterology and Hepatology, Rutgers New Jersey Medical School, Newark, USA

\begin{abstract}
Hepatitis B (HBV) and hepatitis C (HCV) reactivation may occur after the use of biologic agents. During the last decade, utilization of biologics has changed the fate of many treated for cancer, autoimmune and connective tissue disease, maintenance of transplanted organs, and the prevention of graftversus-host disease among others. HBV reactivation has been reported in up to $50 \%$ of HBV carriers undergoing immunosuppressive therapy, and there is emerging data pointing towards an increased risk for HCV reactivation. If reactivation of HBV and HCV occurs, the spectrum of clinical manifestations can range from asymptomatic hepatitis flares to hepatic decompensation, fulminant hepatic failure, and death. Therefore, identifying patients at risk and early diagnosis are imperative to decrease significant morbidity and mortality. The purpose of this article is to review the pathophysiology of the reactivation of $\mathrm{HBV}$ and $\mathrm{HCV}$ infection in patients receiving biologic therapies and the approaches used to diagnose, prevent, and treat $\mathrm{HBV}$ and $\mathrm{HCV}$ reactivation.

(c) 2014 The Second Affiliated Hospital of Chongqing Medical University. Published by XIA \& HE Publishing Ltd. All rights reserved.
\end{abstract}

\section{Introduction}

Chronic hepatitis B (HBV) and C virus (HCV) infection are major causes of morbidity and mortality in the United States (US). It is estimated that approximately 1.3 million and 5.2 million people in the US suffer from chronic HBV and HCV infection, respectively. ${ }^{1,2}$ Both chronic infections can lead to cirrhosis, hepatocellular carcinoma, and liver transplantation. During the last decade, screening guidelines for HBV and HCV have improved to assist in the recognition of populations at higher risk (Table 1 ).

With unprecedented advances in the treatment against cancer, autoimmune and connective tissue diseases,

Keywords: Hepatitis B reactivation; Hepatitis C reactivation; Biologics; Immunosuppressive therapy; Prophylactic antiviral treatment.

Abbreviations: AASLD, American Association for the Study of Liver Disease; ALT, alanine aminotransferase; APASL, Asian Pacific Association for the Study of Liver Disease; DAA, direct acting antiviral agents; EASL, European Association for the Study of Liver Disease; FDA, Food and Drug Administration; HBV, hepatitis B virus; $\mathrm{HBCAb}$, hepatitis B core antibody; $\mathrm{HBsAg}$, hepatitis B surface antigen; HCV, hepatitis C virus; NS, nonstructural; RNA, ribonucleic acid; US, United States; TNF, tumor necrosis factor.

Received: 02 November 2014; Revised: 02 December 2014; Accepted: 08 December 2014

DOI: $10.14218 /$ JCTH.2014.00033.

*Correspondence to: Nikolaos Pyrsopoulos, Division of Gastroenterology and Hepatology, Rutgers New Jersey Medical School, 185 South Orange Ave, MSB, Room H-536, Newark NJ 07101, USA. Tel: +01-973-972-5252, Fax: +01-973972-3144, E-mail: pyrsopni@njms.rutgers.edu transplantation, and the prevention of graft-versus-host disease, data are emerging that point towards an increased risk of HBV and $\mathrm{HCV}$ reactivation after the use of biologics. HBV reactivation has been reported in $20 \%$ to $50 \%$ of HBV carriers undergoing immunosuppressive therapy or chemotherapy. ${ }^{3-6}$ The spectrum of clinical manifestations can range from asymptomatic hepatitis fiares to hepatic decompensation, fulminant hepatic failure, and death. In contrast, HCV reactivation is rare, but if severe hepatitis develops, the mortality rates are similar to that of HBV infected patients. ${ }^{7-13}$ Some of the biologics identified to increase the risk of $\mathrm{HBV}$ and $\mathrm{HCV}$ reactivation include monoclonal antibodies to $T$ and $B$ cells. These include rituximab, alentuzumab, and tumor necrosis factor (TNF)- $\alpha$ antagonist with or without combination therapy (including corticosteroids). ${ }^{14-29}$

Here, we review the pathophysiology of the reactivation of $\mathrm{HBV}$ and $\mathrm{HCV}$ in patients receiving biologic therapy and provide approaches for the diagnosis, prevention, and treatment of $\mathrm{HBV}$ and $\mathrm{HCV}$ reactivation.

\section{Hepatitis $B$ reactivation}

The natural course of HBV infection is determined by the interplay between virus, host, and environment. ${ }^{30}$ The rate of progression from acute to chronic HBV infection ranges from $90 \%$ in newborns, $25 \%$ to $30 \%$ in infants and children under five, and to less than $5 \%$ in adults. ${ }^{31-34}$ Chronic HBV infection can be classified into five phases: immune tolerant, immune active, inactive chronic infection, chronic disease, and recovery. Each phase of infection has characteristic serologic patterns and correlate with the patient's immune response to $\mathrm{HBV}^{31,35-37} \mathrm{~A}$ good understanding of $\mathrm{HBV}$ serologic test results is essential for diagnosis and management (Table 2).

Patients with serologic evidence of resolution, spontaneously or after treatment, show clearance of hepatitis B surface antigen (HBsAg), positive hepatitis B core antibody $(\mathrm{HBCAb})$, and hepatitis B surface antibody (HBsAb). In these patients, the immune system inhibits the replication and gene expression of $\mathrm{HBV}$.

HBV reactivation is defined as the reappearance of active hepatic necroinfiammatory disease in a person known to have the inactive HBsAg carrier state or resolved hepatitis B infection. ${ }^{38-39}$ It has been reported in $20 \%$ to $50 \%$ of HBV carriers undergoing immunosuppressive therapy or chemotherapy. ${ }^{3-6}$ Clinical manifestations include nonspecific symptoms like fatigue, general malaise, jaundice, hepatic decompensation, fulminant hepatic failure manifested with hepatic encephalopathy, coagulopathy, and even death. Patients can also present with asymptomatic hepatitis fiares identified only by biochemical and molecular profiling. 
Bojito-Marrero L. et al: Chronic hepatitis B and hepatitis C reactivation in the biologic era

Table 1. American Association for the Study of Liver Disease (AASLD) screening guidelines for HBV and HCV

AASLD screening guidelines for HBV and HCV

HBV

- Individuals born in areas of high or intermediate prevalence rates

for HBV, including immigrants and adopted children ${ }^{a}$

- US born persons not vaccinated as infants whose parents were born in regions with high HBV endemicity

- Household and sexual contacts of HBsAg-positive persons

- People who have ever injected drugs

- People with multiple sexual partners or history of sexually

transmitted disease

- Men who have sex with men

$\mathrm{HCV}$

- At least once in people born between 1945-1965

- People who have use injected or intranasal illicit drugsin the recent and remote past, including those who injected only once and do not consider themselves to be drug users

- People with conditions associated with a high prevalence of HCV infection, including people with:

- HIV infection

- Hemophilia who received clotting factor concentrates prior to 1987

- People who have ever been on hemodialysis

- People who were incarcerated

- People who received tattoos in unregulated settings

- Unexplained abnormal aminotransferase levels
- Inmates of correctional facilities

- Individuals with chronically elevated ALT or AST

- Individuals infected with HCV or HIV

- Patients undergoing renal dialysis

- All pregnant women

- Persons needing immunosuppressive therapy
- Prior recipients of transfusions or organ transplants prior to July 1992 including persons who: - Were notified that they had received blood from a donor who later tested positive for $\mathrm{HCV}$ infection

- Received a transfusion of blood or blood products

- Received an organ transplant

- Children born to HCV-infected mothers

- Health care, emergency medical and public safety workers after a needle stick injury or mucosal exposure to HCV-positive blood

- Current sexual partners of HCV-infected persons - Annual testing for people with ongoing risk factors for HCV exposure

${ }^{a}$ Areas of high or intermediate prevalence rate for HBV: Asia, Africa, South Pacific Islands, Middle East (except Cyprus and Israel), European Mediterranean (Malta and Spain), The Arctic (indigenous populations of Alaska, Canada, and Greenland), South America (Ecuador, Guyana, Suriname, Venezuela, and Amazon regions of Bolivia, Brazil, Colombia, and Peru), Eastern Europe (all countries except Hungary), Caribbean (Antigua and Barbuda, Dominica, Granada, Haiti, Jamaica, St. Kitts and Nevis, St. Lucia, and Turks and Caicos), Central America (Guatemala and Honduras).

The timing of reactivation after treatment with biologics is variable. The proposed mechanism of HBV reactivation is divided into three stages. $7,38-40$ The initial stage is characterized by viral replication, which is due to the host's decreased immune response. During this stage, serum levels of HBV DNA, HBeAg, and HBsAg are increased, and HBsAb level is decreased. Immunosuppressive agents, such as corticosteroids, may also play a stimulatory role in the production of HBV DNA.
The second stage occurs after the discontinuation of biologics and immune reconstitution. Infected hepatocytes are identified as carrying viral antigens and undergo cytotoxic T cell mediated destruction. During this stage, there is active hepatic necroinflammation with an elevation of the aminotransferases and a potential decrease of HBV DNA.

The third stage is the recovery phase, where there is resolution of the necroinflammation, normalization of the aminotransferases, and decrease of HBV DNA to baseline.

Table 2. Interpretation of HBV serologic test results

\begin{tabular}{|c|c|c|c|c|c|c|c|}
\hline \multicolumn{8}{|c|}{ Interpretation of HBV serologic test results } \\
\hline & HBsAg & HBsAb & $\begin{array}{l}\text { HBcAb } \\
\text { IgM }\end{array}$ & $\begin{array}{l}\mathrm{HBcAb} \\
\mathrm{IgG}\end{array}$ & HBeAg & $\mathrm{HBeAb}$ & HBV DNA \\
\hline Acute & + & - & + & - & + & - & + \\
\hline Resolved HBV & - & + & - & + & - & + & - \\
\hline Inactive carrier state & + & - & - & $+/-$ & - & + & - \\
\hline Chronic HBV & + & - & - & $+/-$ & $+/-$ & - & + \\
\hline Vaccine induced immunity & - & + & - & - & - & - & - \\
\hline
\end{tabular}

HBsAg: hepatitis B surface antigen; HBsAb: hepatitis B surface antibody; HBcAb: hepatitis B core antibody; HBeAg: hepatitis b envelope antigen; HBeAb: hepatitis B envelope antibody. 
Bojito-Marrero L. et al: Chronic hepatitis B and hepatitis C reactivation in the biologic era

This phase is not observed in patients with fulminant hepatic failure or death. Patients with evidence of acute on chronic liver disease are at higher risk of developing liver failure. ${ }^{39}$

In a systematic review encompassing all studies from 2006-2010, 25 articles with a total of 35 cases of HBV reactivation subsequent to TNF- $\alpha$ inhibitors were identified. ${ }^{16}$ All 35 cases were HBsAg positive prior to initiation of the inhibitors. Indications for treatment included rheumatoid arthritis, Crohn's disease, and ankylosing spondylitis. Infliximab was used in 17 cases, etanercept in 12 cases, and adalimumab in six cases. Infliximab was associated with a greater than 2-fold increase in alanine aminotransferase (six of nine cases) and greater than 1,000-fold increase in HBV DNA viral load (three of four cases). Two deaths were reported with the use of infliximab.

Pei et al. identified 115 B cell lymphoma patients who received rituximab-containing therapy. HBsAg positivity was found in 15 patients, where five received lamivudine prophylaxis and did not develop HBV-related hepatitis. Eight of 10 patients who were HBsAg positive without lamivudine prophylaxis experienced HBV-related hepatitis, including one fatal hepatic failure. Four (4.2\%) of $95 \mathrm{HBsAg}$ negative patients experienced seroconversion and developed de novo HBVrelated hepatitis, two of which died of fulminant hepatitis. ${ }^{17}$

Rituximab, a chimeric monoclonal antibody against the protein CD20 in B cells, is a major risk factor for the development of HBV reactivation. It causes apoptosis of $B$ cells, therein limiting the immunehost response towards HBV by decreasing antigen presenting cell activity and cytotoxic response of CD8 T lymphocytes. $7,38-40$

\section{Hepatitis B reactivation prevention and treatment}

HBV reactivation related morbidity and mortality rates can be reduced by identifying early patients at risk and initiating prophylactic antiviral treatment. ${ }^{31,40-46}$ The Asian Pacific Association for the Study of Liver Disease (APASL) recommends that all patients in need of the use of biologics and other immunosuppressive therapy should be screened for HBsAg prior to utilization of treatment (Table 3). ${ }^{59}$ The American Association for the Study of Liver Disease (AASLD) and the European Association for the Study of Liver Disease (EASL) recommend performing HBV serologies and liver function tests to diagnose HBV infection. ${ }^{31,45}$ If there is evidence of past or present HBV infection, quantitative HBV DNA viral load should be tested, and patients should be referred to a hepatologist for evaluation. Both active and inactive carriers need to start prophylactic antiviral treatment. Following the most recent guidelines issued by the AASLD and EASL, HBsAg positive patients should be treated with lamivudine or telbivudine if the anticipated duration of treatment is less than 12 months and baseline serum HBV DNA is not detectable. Tenofovir or entecavir is preferred if a longer treatment duration is anticipated. Patients with baseline HBV DNA $<2,000 \mathrm{IU} / \mathrm{mL}$ should continue treatment for 6 months after completion of chemotherapy or immunosuppressive therapy, while patients with higher baseline HBV DNA levels should continue the same treatment strategy as immunocompetent patients. ${ }^{31,45}$

HBsAg-negative patients with positive HBcAb should be tested for HBV DNA. Such patients with detectable serum HBV DNA need to start prophylactic antiviral treatment. However, if HBV DNA is undetectable, current data is insufficient to advocate for the use of prophylactic antiviral treatment. In that case, very close follow up of alanine aminotransferase (ALT) and HBV DNA testing is necessary, and prophylactic antiviral treatment should be initiated if HBV DNA becomes detectable (Fig. 1). EASL guidelines recommend monitoring every 1-3 months, depending on the type of immunosuppressive therapy and comorbidities (Table 4).

\section{Hepatitis C reactivation}

Approximately 5.2 million people in the US suffer from chronic HCV infection. ${ }^{2}$ Among patients exposed to $\mathrm{HCV}$, up to $85 \%$ will become chronically infected, and $5-25 \%$ of those cases will develop cirrhosis after 10 years. ${ }^{47}$ In contrast to $\mathrm{HBV}$ reactivation, HCV reactivation is very uncommon. ${ }^{7-13}$ Following immunosuppressive therapy, an increase of viral load to at least one $\log 10 \mathrm{IU} / \mathrm{mL}$ above the baseline has been reported. ${ }^{13,39,48}$ The clinical manifestations of HCV reactivation may vary from asymptomatic to at least a three-fold increase in aminotransferases. Cases of severe hepatic failure have been reported. ${ }^{7-13,39,48}$

The incidence of hepatic toxicity in HCV infected patients receiving chemotherapy is higher than in patients without $\mathrm{HCV}$ infection. Mahale et al. reported HCV reactivation in $36 \%$ of patients with chronic HCV and cancer. ${ }^{13}$ It was difficult to identify the specific chemotherapeutic agents causing hepatotoxicity in the Mahale study, as various agents were utilized. The most commonly used agents preceding HCV reactivation were cytarabine, etoposide, and rituximab. Other reports have been published regarding potential HCV reactivation when utilizing rituximab. ${ }^{13,25-28}$

Aksoy et al. reported a case of a patient with history of $\mathrm{HCV}$ cirrhosis who presented with a breast lesion due to large B-cell lymphoma. ${ }^{26}$ The patient was treated with rituximab monotherapy for three consecutive weeks, but treatment had to be discontinued as a result of hematological toxicity. The $\mathrm{HCV}$ viral load was increased three and ten weeks after therapy, but the biochemical profile remained unchanged. After discontinuation of rituximab, the viral load decreased gradually. Tsutsumi et al. also reported increases in HCV viral load in four patients receiving rituximab for the treatment of non-Hodgkin's lymphoma. ${ }^{27}$ The HCV viral load was elevated after the administration of rituximab or a rituximab containing regimen, and, in one case, viral load was decreased after switching to a treatment without rituximab. The pathogenesis of $\mathrm{HCV}$ reactivation following immunosuppressives remains to be elucidated, although an increase in HCV replication as a

Table 3. APASL screening and treatment guidelines for HBV prior to utilization of biologics

APASL screening and treatment guidelines for HBV prior to utilization of biologics

All candidates for chemotherapy and immunosuppressive therapy should be screened for HBsAg prior to utilization of treatment. If HBsAg (+) patients should start nucleoside/nucleotide analogues if clinically indicated.

Start preemptive therapy with lamivudine up to at least 6 months after the end of immunosuppression or chemotherapy. 
Bojito-Marrero L. et al: Chronic hepatitis B and hepatitis C reactivation in the biologic era

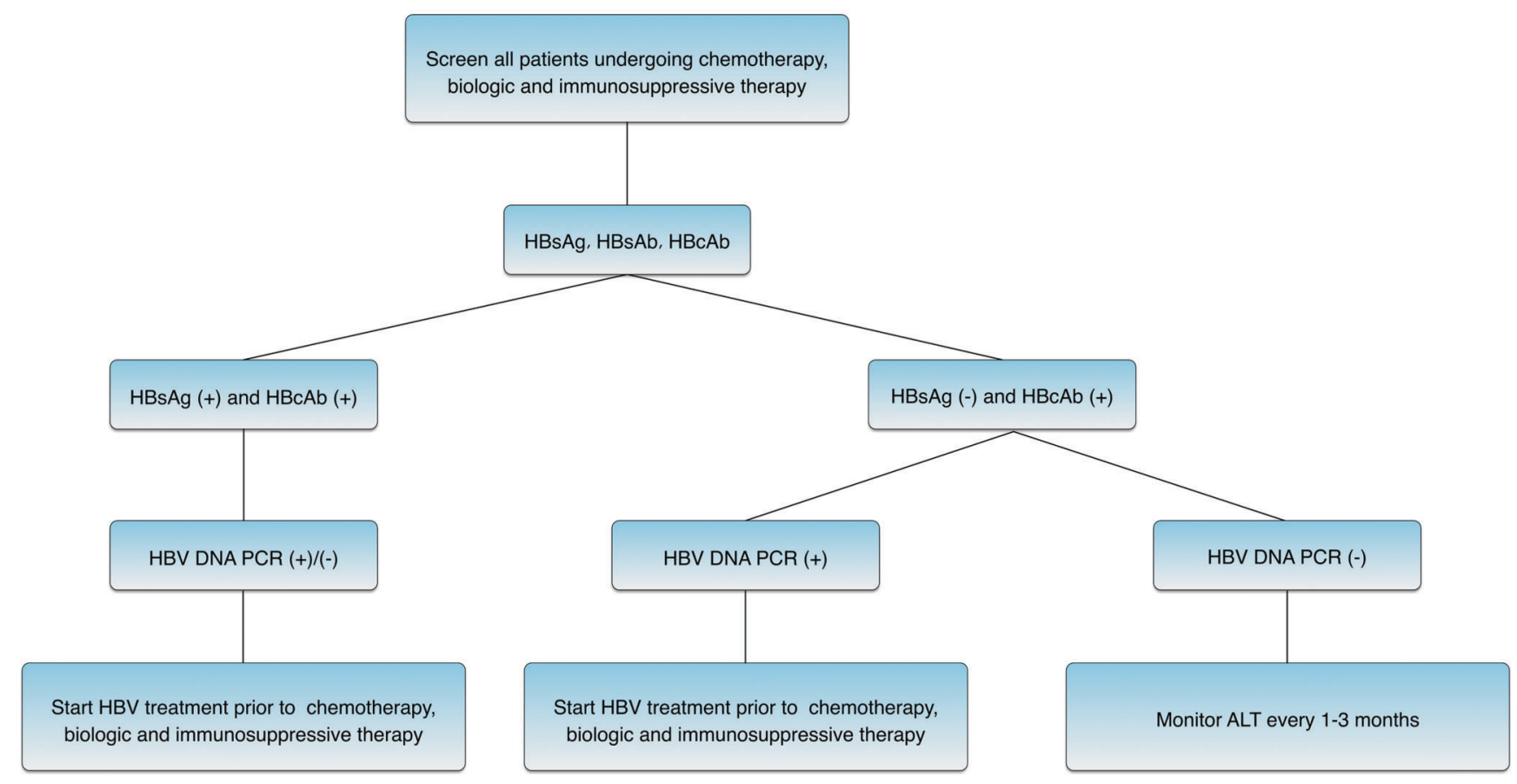

Fig. 1. Algorithm for the management of HBV reactivation. All patients in need of the use of biologics and other immunosuppressive therapy must have HBV serologiesto diagnose HBV infection. HBsAg-positive and HBCAb-negative patients should be treated with lamivudine or telbivudine if the anticipated duration of treatment is less than 12 months and baseline serum HBV DNA is not detectable. Tenofovir or entecavir is preferred if longer duration of treatment is anticipated. HBsAg-negative patients with positive HBCAb should be tested for HBV DNA. Such patients with detectable serum HBV DNA need to start prophylactic antiviral treatment. However, if HBV DNA is undetectable, current data is insufficient to advocate for the use prophylactic antiviral treatment. In that case, very close follow up of ALT and HBV DNA testing every $1-3$ months is necessary, and prophylactic antiviral treatment should be initiated if HBV DNA becomes detectable.

direct cytopathic effect has been postulated. ${ }^{10,40}$ This, followed by the reconstitution of the immune system upon discontinuation of immunosuppressive agents, might lead to direct hepatotoxicity and cell death.

Recurrence of HCV has also been reported in patients after solid organ transplant. ${ }^{47,49-52}$ After liver transplant, HCV recurrence is universal and the majority of patients will demonstrate histological evidence within the first year after transplantation. Accelerated progression of fibrosis is seen in $6-23 \%$ of patients, who will develop cirrhosis after a median of 3.4 years. The exact mechanism by which this occurs is unknown, although immunosuppressive therapy is thought to play an important role. ${ }^{47}$ Similarly, studies performed on various solid organ transplants, including patients with

Table 4. EASL screening and treatment guidelines for HBV and HCV prior to utilization of biologics

EASL screening and treatment guidelines for HBV prior to utilization of biologics

All candidates for chemotherapy and immunosuppressive therapy should be screened for HBsAg and HBcAb prior to utilization of treatment.

Vaccination of HBV seronegative patients is highly recommended.

HBV DNA levels should be tested in HBsAg (+) patients, and preemptive nucleoside/nucleotide analogues started during therapy and for 12 months after cessation of therapy.

Patients with HBV DNA level $<2,000 \mathrm{IU} / \mathrm{mL}$ should be treated with lamivudine if a short duration with immunosuppressives is expected.

Patients with high HBV DNA level or immunosuppressive therapy of long duration should be treated with entecavir or Tenofovir, which are agents with high antiviral potency and high barrier to resistance.

Patients with HBsAg (-) and HBCAb (+) should have ALT and HBV DNA levels monitored every 1-3 months. These patients should be treated upon confirmation of HBV reactivation.

Some experts recommend prophylaxis with lamivudine in all HBsAg $(-)$ and HBCAb (+) patients who receive rituximab and/or combined regimens for hematological malignancies, if they are HBsAb $(-)$ and/or if close monitoring of HBV DNA level is not guaranteed.

Prophylaxis with nucleoside/nucleotide analogues is also recommended for $\mathrm{HBcAb}(+)$ patients receiving bone marrow or stem cell transplantation. 
Bojito-Marrero L. et al: Chronic hepatitis B and hepatitis C reactivation in the biologic era

chronic HCV, have reported higher mortality rates due to liver related causes. ${ }^{47,53}$

The evidence regarding HCV infection and the use of a TNF- $\alpha$ antagonist is rather different. In a double-blind, randomized, placebo controlled trial; 50 patients with chronic $\mathrm{HCV}$ were randomly assigned to receive interferon alfa- $2 \mathrm{~b}$ and ribavirin with either etanercept or placebo for 24 weeks. The results showed that patients in the etanercept plus standard antiviral therapy group had substantially greater viral suppression than the standard antiviral therapy group, $63 \%$ vs. $32 \%$, respectively. ${ }^{54}$

\section{Hepatitis C reactivation prevention and treatment}

Despite the fact the rate of HCV reactivation is very low, during or after the use of biologic and other immunosuppressive agents, it still remains a significant cause of morbidity. ${ }^{55}$ Optimally, these patients would undergo screening for HCV prior to initiation of treatment. Until more prospective studies demonstrate this relationship, caution should be exercised and careful monitoring is recommended for patients with $\mathrm{HCV}$.

Current treatment for HCV infection is rapidly evolving. In 2011, we experienced the beginning of a new era with the Food and Drug Administration (FDA) approval of a new group of direct acting antiviral agents (DAA), namely telaprevir and boceprevir. Since late 2013, additional DAAs, such as sofosbuvir, simeprevir and ladipasvir, were included in the therapeutic armamentarium against HCV. Sofosbuvir is the prodrug of a nucleotide analogue inhibitor of the HCV nonstructural (NS) 5B ribonucleic acid (RNA)dependent RNA polymerase. ${ }^{56-58}$ Simeprevir is a specific inhibitor of the HCV NS3/4A serine protease. ${ }^{58}$ In October 10,2014 , the ledipasvir/sofosbuvir combination therapy of DAAs was approved by the FDA for patients with genotype 1. Currently, the next generation of DAAs, including paritaprevir, ombitasvir, dasabuvir, daclatasvir, and asunaprevir among others, are being evaluated by the FDA and other international agencies. Although the guidelines regarding the utilization of the new DAAs should be reviewed prior to or during the utilization of the chemotherapeutic agents, it might be beneficial to consider testing these patients in order to avoid reactivation of the HCV disease.

\section{Differences between $\mathrm{HBV}$ and $\mathrm{HCV}$ reactivation}

As previously mentioned, HBV reactivation has been reported in $20-50 \%$ of HBV carriers undergoing immunosuppressive therapy or chemotherapy. ${ }^{3-6}$ In contrast, HCV reactivation is rare, although the morbidity and mortality rates are similar to that of HBV reactivation. ${ }^{7-13}$ The high incidence of HBV reactivation has allowed researchers to identify three stages of pathogenesis. ${ }^{7,38-40}$ These are characterized by viral replication in response to decreased host immunity, immune reconstitution and active hepatic necroinflammation of infected hepatocytes mediated by cytotoxic T cells, and resolution of necroinflammation.

There are still knowledge gaps in the pathogenesis of $\mathrm{HCV}$ reactivation following immunosuppressives, but it is thought to be related to an increase in HCV replication leading to direct hepatotoxicity and cell death. ${ }^{10,40}$

\section{Conclusions}

Over the last decade, the utilization of biologics and immunosuppressive agents for the treatment of cancer and autoimmune diseases has increased, accentuating the need for HBV and HCV screening. Data suggest that the risk for HBV and HCV reactivation is increased during and after the use of biologics. Efforts should be directed towards early recognition in order to decrease morbidity and mortality. Active HBV patients and inactive carriers should be carefully monitored, and prophylactic antiviral treatment should be started preemptively.

The possibility of $\mathrm{HCV}$ reactivation during the use of biologics and chemotherapeutic agents remains to be determined. There is a significant gap in available information, and this lack of datapoints towards an increased need for prospective studies targeting this population. Until more data become available, caution should be exercised and liver enzymes and the viral load should be monitored closely in vulnerable patients.

\section{Conflict of interest}

None

\section{Author contributions}

Design of paper, review of the literature, evaluation of papers that should be utilized as references and drafting the paper (LBM); review of references, drafting the paper and performing revisions, review of the paper and final approval (NP).

\section{References}

[1] Weinbaum CM, Mast EE, Ward JW. Recommendations for identification and public health management of persons with chronic hepatitis B virus infection. Hepatology 2009;49:S35-S44. doi: 10.1002/hep.22882.

[2] Chak E, Talal AH, Sherman KE, Schiff ER, Saab S. Hepatitis C virus infection in USA: an estimate of true prevalence. Liver Int 2011;31:1090-1101. doi: 10.1111/j.1478-3231.2011.02494.x.

[3] Yeo W, Zee B, Zhong S, Chan PKS, Wong W-L, Ho WM, et al. Comprehensive analysis of risk factors associating with hepatitis $\mathrm{B}$ virus reactivation in cancer patients undergoing cytotoxic chemotherapy. Br J Cancer 2004;90: 1306-1311 doi: 10.1038/sj.bjc.6601699.

[4] Lok AS, Liang RH, Chiu EK, Wong KL, Chan TK, Todd D. Reactivation of hepatitis B virus replication in patients receiving cytotoxic therapy. Report of a prospective study. Gastroenterology 1991;100:182-188.

[5] Nakamura Y, Motokura T, Fujita A, Yamashita T, Ogata E. Severe hepatitis related to chemotherapy in hepatitis $B$ virus carriers with hematologic malignancies. Survey in Japan, 1987-1991. Cancer 1996;78:2210-2215. doi: 10.1002/(SICI)1097-0142(19961115)78:10<2210: :AID-CNCR24> 3.0.CO;2-0.

[6] Kumagai K, Takagi $T$, Nakamura $S$, Sawada $U$, Kura $Y$, Kodama $F$, et al. Hepatitis B virus carriers in the treatment of malignant lymphoma: an epidemiological study in Japan. Ann Oncol 1997;8(Suppl 1):107-109.

[7] Torres HA, Davila M. Reactivation of hepatitis B virus and hepatitis C virus in patients with cancer. Nat Rev ClinOncol 2012;9:156-166. doi: 10.1038 /nrclinonc.2012.1.

[8] Zuckerman E, Zuckerman T, Douer D, Qian D, Levine AM. Liver dysfunction in patients infected with hepatitis $C$ virus undergoing chemotherapy for hematologic malignancies. Cancer 1998;83:1224-1230. doi: 10.1002 /(SICI)1097-0142(19980915)83:6<1224::AID-CNCR23>3.0.CO;2-6.

[9] Luppi M, Longo G, Ferrari MG, Ferrara L, Marasca R, Barozzi P, et al. Additional neoplasms and HCV infection in low-grade lymphoma of MALT type. Br J Haematol 1996;94:373-375.

[10] Vento S, Cainelli F, Mirandola F, Cosco L, Di Perri G, Solbiati M, et al. Fulminant hepatitis on withdrawal of chemotherapy in carriers of hepatitis $C$ virus. Lancet 1996;347:92-93. doi: 10.1016/S0140-6736(96)90212-3.

[11] Kawatani T, Suou T, Tajima F, Ishiga K, Omura H, Endo A, et al. Incidence of hepatitis virus infection and severe liver dysfunction in patients receiving 
chemotherapy for hematologic malignancies. Eur J Haematol 2001;67:45-50. doi: 10.1034/j.16000609.2001.067001045.x.

[12] Vento S, Cainelli F, Longhi MS. Reactivation of replication of hepatitis B and C viruses after immunosuppressive therapy: an unresolved issue. Lancet Oncol 2002;3:333-340. doi: 10.1016/S1470-2045(02)00773-8.

[13] Mahale P, Kontoyiannis DP, Chemaly RF, Jiang Y, Hwang JP, Davila M, et al. Acute exacerbation and reactivation of chronic hepatitis $C$ virus infection in cancer patients. J Hepatol 2012;57:1177-1185. doi: 10.1016/j.jhep. 2012.07.031.

[14] Yeo W, Johnson PJ. Diagnosis, prevention and management of hepatitis B virus reactivation during anticancer therapy. Hepatology 2006;43:209-220. doi: $10.1002 /$ hep. 21051.

[15] Lubel JS, Angus PW. Hepatitis B reactivation in patients receiving cytotoxic chemotherapy: diagnosis and management. J Gastroenterol Hepatol 2010; 25:864-871. doi: 10.1111/j.1440-1746.2010.06243.x.

[16] Carroll MB, Forgione MA. Use of tumor necrosis factor alpha inhibitors in hepatitis B surface antigen-positive patients: a literature review and potential mechanisms of action. Clin Rheumatol 2010;29:1021-1029. doi: 10.1007/s10067-010-1523-2.

[17] Pei SN, Chen $\mathrm{CH}$, Lee CM, Wang MC, Ma MC, Hu TH, et al. Reactivation of hepatitis $\mathrm{B}$ virus following rituximab-based regimens: a serious complication in both HBsAg-positive and HBsAg-negative patients. Ann Hematol 2010;89: 255-262. doi: 10.1007/s00277-009-0806-7.

[18] Sera T, Hiasa Y, Michitaka K, Konishi I, Matsuura K, Tokumoto Y, et al. Anti-HBspositive liver failure due to hepatitis $B$ virus reactivation induced by rituximab. Intern Med 2006;45:721-724. doi: 10.2169/internalmedicine.45.1590.

[19] Iannitto E, Minardi V, Calvaruso G, Mulè A, Ammatuna E, Di Trapani R, et al. Hepatitis B virus reactivation and alemtuzumab therapy. Eur J Haemato $2005 ; 74: 254-258$. doi: 10.1111/j.1600-0609.2004.00375.x.

[20] Moses SE, Lim ZY, Sudhanva M, Devereux S, Ho AY, Pagliuca A, et al. Lamivudine prophylaxis and treatment of hepatitis $B$ Virus-exposed recipients receiving reduced intensity conditioning hematopoietic stem cell transplants with alemtuzumab. J Med Virol 2006;78:1560-1563. doi: 10.1002/jmv. 20705.

[21] Mitka M. FDA: Increased HBV Reactivation Risk withOfatumumab or Rituximab. JAMA 2013;310:1664. doi: 10.1001/jama.2013.281115.

[22] Dong HJ, Ni LN, Sheng GF, Song HL, Xu JZ, Ling Y. Risk of hepatitis B virus reactivation in non-Hodgkin lymphoma patients receiving rituximab-chemotherapy: A meta-analysis. J Clin Virol 2013;57:209-214. doi: 10.1016/ j.jcv.2013.03.010.

[23] Lee YH, Bae SC, Song GG. Hepatitis B virus reactivation in rheumatic patients with hepatitis core antigen (HBV occult carriers) undergoing anti-tumor necrosis factor therapy. Clin Exp Rheumatol 2013;31:118-121.

[24] Sheen IS, Liaw YF, Lin SM, Chu CM. Severe clinical rebound upon withdrawal of corticosteroid before interferon therapy: incidence and risk factors. J Gastroenterol Hepatol 1996;11:143-147.

[25] Ennishi D, Maeda Y, Niitsu N, Kojima M, Izutsu K, Takizawa J, et al. Hepatic toxicity and prognosis in hepatitis $\mathrm{C}$ virus-infected patients with diffuse large B-cell lymphoma treated with rituximab-containing chemotherapy regimens: a Japanese multicenter analysis. Blood 2010;116:5119-5125. doi: 10.1182/blood-2010-06-289231.

[26] Aksoy S, Abali H, Kilickap S, Erman M, Kars A. Accelerated hepatitis C virus replication with rituximab treatment in a non-Hodgkin's lymphoma patient. Clin Lab Haematol 2006;28:211-214. doi: 10.1111/j.1365-2257.2006.00779.x.

[27] Tsutsumi $Y$, Ichiki K, Shiratori S, Kawamura T, Tanaka J, Asaka M, et al. Changes in hepatitis $C$ virus antibody titer and viral RNA load in nonHodgkin's lymphoma patients after rituximab chemotherapy. Int J Lab Hematol 2009;31:468-470. doi: 10.1111/j.1751-553X.2008.01034.x.

[28] Nooka A, Shenoy P J, Sinha R, Lonial S, Flowers CR. Hepatitis C reactivation in patients who have diffuse large $B$-cell lymphoma treated with rituximab: $a$ case report and review of literature. Clin Lymphoma Myeloma Leuk $2011 ; 11$ : 379-384. doi: 10.1016/j.clml.2011.04.005.

[29] Ciesek S, Steinmann E, Iken M, Ott M, Helfritz FA, Wappler I, et al. Glucocorticosteroids Increase Cell Entry by Hepatitis C Virus. Gastroenterology 2010;138:1875-1884. doi: 10.1053/j.gastro.2010. 02.004.

[30] Liu C], Kao JH. Genetic variability of hepatitis B virus and response to antiviral therapy. Antivir Ther 2008;13:613-624.

[31] Lok ASF, McMahon B]. Chronic hepatitis B: update 2009. Hepatology 2009; 50:661-662. doi: 10.1002/hep.23190.

[32] Coursaget $P$, Yvonnet B, Chotard J, Vincelot P, Sarr M, Diouf C, et al. Age- and sex-related study of hepatitis $B$ virus chronic carrier state in infants from an endemic area (Senegal). J Med Virol 1987;22:1-5. doi: 10.1002/jmv.189 0220102

[33] McMahon BJ, Alward WL, Hall DB, Heyward WL, Bender TR, Francis DP, et al. Acute hepatitis $B$ virus infection: relation of age to the clinical expression of disease and subsequent development of the carrier state. J Infect Diseases 1985;151:599-603. doi: 10.1093/infdis/151.4.599.
[34] Tassopoulos NC, Papaevangelou G], Sjogren MH, Roumeliotou-Karayannis A Gerin JL, Purcell RH. Natural history of acute hepatitis B surface antigenpositive hepatitis in Greek adults. Gastroenterology 1987;92:1844-1850.

[35] http://emedicine.medscape.com/article/177632, accessed December, 2013.

[36] Tran TT. Immune tolerant hepatitis B: a clinical dilemma. Gastroenterol Hepatol 2011;7:511-516.

[37] Liaw YF, Chu CM. Hepatitis B virus infection. Lancet 2009;373:582-592. doi: 10.1016/S0140-6736(09)60207-5.

[38] Hoofnagle JH. Reactivation of hepatitis B. Hepatology 2009;49:S156-S165. doi: 10.1002/hep.22945.

[39] Mastroianni CM, Lichtner M, Citton R, Del Borg C, Rago A, Martini H, et al. Current trends in management of hepatitis $B$ virus reactivation in the biologic therapy era. World J Gastroenterol 2011;17:3881-3887. doi: 10.3748/ wjg.v17.i34.3881.

[40] Watanabe T, Tanaka Y. Reactivation of hepatitis viruses following immunomodulating systemic chemotherapy. Hepatol Res 2013;43:113-121. doi: 10.1111/hepr.12014

[41] Huang YH, Hsiao LT, Hong YC, Chiou TJ, Yu YB, Gau JP, et al. Randomized controlled trial of entecavir prophylaxis for rituximab-associated hepatitis $B$ virus reactivation in patients with lymphoma and resolved hepatitis B. J Clin Oncol 2013;31:2765-2772. doi: 10.1200/JCO.2012.48.5938.

[42] Loomba R, Rowley A, Wesley R, Liang TJ, Hoofnagle JH, Pucino F, et al. Systematic review: the effect of preventive lamivudine on hepatitis $B$ reactivation during chemotherapy. Ann Intern Med 2008;148:519-528. doi: 10.7326/0003-4819-148-7-200804010-00008.

[43] Li HR, Huang JJ, Guo HQ, Zhang X, Xie Y, Zhu HL, et al. Comparison of entecavir and lamivudine in preventing hepatitis $\mathrm{B}$ reactivation in lymphoma patients during chemotherapy. J Viral Hepat 2011;18:877-883. doi: 10.1111/j.13652893.2010.01386.x.

[44] Fung J, Cheung C, Chan SC, Yuen MF, Chok KS, Sharr W, et al. Entecavir monotherapy is effective in suppressing hepatitis B virus after liver transplantation. Gastroenterology 2011;141:1212-1219. doi: $10.1053 / \mathrm{j}$ .gastro.2011.06.083.

[45] European Association For The Study Of The Liver, Papatheodoridis G, Buti M, Cornberg M, Janssen HL, Mutimer D, et al. EASL Clinical Practice Guidelines: Management of chronic hepatitis B virus infection. J Hepatol 2012;57:167185. doi: 10.1016/j.jhep.2012.02.010.

[46] Sperl J, Frankova S, Kieslichova E, Oliverius M, Janousek L, Honsova E, et al. Urgent liver transplantation for chemotherapy-induced HBV reactivation: $A$ suitable option in patients recently treated for malignant lymphoma. Transplant Proc 2013;45:2834-2837. doi: 10.1016/j.transproceed.2013. 03.047.

[47] Ghany MG, Strader DB, Thomas DL, Seeff LB. Diagnosis, management, and treatment of hepatitis C: an update. Hepatology 2009;49:1335-1374. doi: 10.1002/hep.22759.

[48] Morisco F, Castiglione F, Rispo A, Stroffolini T, Sansone S, Vitale R, et al. Effect of immunosuppressive therapy on patients with inflammatory bowel diseases and hepatitis B or C virus infection. J Viral Hepat 2013;20:200 208. doi: 10.1111/j.1365-2893.2012.01643.x.

[49] European Association for the Study of the Liver. EASL Clinical Practice Guidelines: Management of hepatitis C virus infection. J Viral Hepat 2014 60:392-420. doi: 10.1016/j.jhep.2013.11.003.

[50] Ghobrial RM, Steadman R, Gornbein J, Lassman C, Holt CD, Chen P, et al. A 10-year experience of liver transplantation for hepatitis $\mathrm{C}$ : analysis of factors determining outcome in over 500 patients. Ann Surg 2001;234:384-393. doi: 10.1097/00000658-200109000-00012.

[51] Garcia-Retortillo M, Forns X, Feliu A, Moitinho E, Costa J, Navasa M, et al. Hepatitis $C$ virus kinetics during and immediately after liver transplantation. Hepatology 2002;35:680-687. doi: 10.1053/jhep.2002.31773.

[52] Neumann UP, Berg T, Bahra M, Puhl G, Guckelberger O, Langrehr JM, et al. Long-term outcome of liver transplants for chronic hepatitis C: a 10-year follow-up. Transplantation 2004;77:226-231. doi: 10.1097/01.TP.000010 1738.27552.9D

[53] Haji SA, Starling RC, Avery RK, Mawhorter S, Tuzcu EM, Schoenhagen P, et al. Donor hepatitis-C seropositivity is an independent risk factor for the development of accelerated coronary vasculopathy and predicts outcome after cardiac transplantation. J Heart Lung Transplant 2004;23:277-283. doi: 10.1016/S1053-2498(03)00148-7.

[54] Zein NN. Etanercept as an adjuvant to interferon and ribavirin in treatmentnaive patients with chronic hepatitis $C$ virus infection: a phase 2 randomized double-blind, placebo-controlled study. J Hepatol 2005;42:315-22. doi: 10.1016/j.jhep.2004.11.025.

[55] http://www.hcvguidelines.org/sites/default/files/full_report.pdf, accessed February, 2014

[56] Lawitz E, Mangia A, Wyles D, Rodriguez-Torres M, Hassanein T, Gordon SC, et al. Sofosbuvir for previously untreated chronic hepatitis $C$ infection. N Engl J Med 2013;368:1878-1887. doi: 10.1056/NEJMoa1214853. 
Bojito-Marrero L. et al: Chronic hepatitis B and hepatitis C reactivation in the biologic era

[57] Zeuzem S, Dusheiko GM, Salupere R, Mangia A, Flisiak R, Hyland RH, et al. Sofosbuvir + Ribavirin for 12 or 24 weeks for patients with HCV genotype 2 or 3: the VALENCE trial. Hepatology 2013;58(Suppl):733A.

[58] Jacobson IM, Ghalib RH, Rodriguez-Torres M, Younossi ZM, Corregidor A, Sulkowski MS, et al. SVR results of a once-daily regimen of simeprevir (TMC435) plus sofosbuvir (GS-7977) with or without ribavirin in cirrhotic and non-cirrhotic HCV genotype 1 treatment-naive and prior null responder patients: The COSMOS study. Hepatology 2013;58(Suppl):1379A.

[59] Liaw YF, Kao JH, Piratvisuth T, Chan HL, Chien RN, Liu CJ, et al. AsianPacific consensus statement on the management of chronic hepatitis $\mathrm{B}$ : a 2012 update. Hepatol Int 2012;6:531-561. doi: 10.1007/s12072-0129365-4. 